\title{
Numerical Simulation of Zr-based Bulk Metallic Glass During Continuous Casting Solidification Process
}

\author{
Renhong Tang ${ }^{a}$, Bingwen Zhou ${ }^{a}$,Yuejiao Ma ${ }^{a}$, Fei Jia ${ }^{a *}$, Xingguo Zhang ${ }^{a}$ \\ ${ }^{a}$ School of Materials Science and Engineering, Dalian University of Technology, Dalian 116024, China
}

Received: August 22, 2014; Revised: April 12, 2015

\begin{abstract}
A numerical simulation method was used to analyze the solidification process of Zr-based bulk metallic glass (BMG) during the horizontal continuous casting (HCC) process. The large-scale general-purpose finite element analysis software ANSYS was adopted to develop a temperature field model. The variation of temperature field in the specific area at different time was studied. Its accuracy was verified by the experimental results of $\mathrm{Zr}_{48} \mathrm{Cu}_{36} \mathrm{Ag}_{8} \mathrm{Al}_{8}$ bulk metallic glass continuous casting solidification process. The effects of casting parameters include intermittent casting procedure (drawing and stopping), casting speed, pouring temperature and cooling rate. The results show that the optimum casting speed range is $1-2 \mathrm{~mm} / \mathrm{s}$, pouring temperature is $1223 \mathrm{~K}$ and cooling rate of $10 \mathrm{~mm}$ rod casting is $5 \mathrm{~L} / \mathrm{min}$ respectively. A fully $\mathrm{Zr}$-based bulk metallic glass whose diameter is $10 \mathrm{~mm}$ and length has no limitation has been successfully fabricated.
\end{abstract}

Keywords: bulk metallic glass, continuous casting, composite water cold copper-graphite mold, numerical simulation of casting process, temperature field

\section{Introduction}

For the past two decades, the application of numerical simulation which can help researchers solve sophisticated problems has made significant contributions to materials science and metallurgical industry due to its functions ${ }^{1-5}$. As an important branch of the industrial system, metallic glass have been commercialized in several fields such as engineering, medicine, electronics, military, sports, and jewelry making for a period of time $\mathrm{e}^{6-10}$. A variety of bulk glassy alloys have been developed in lanthanide ( $\mathrm{Ln})^{\left[{ }^{[11]}\right]}, \mathrm{Mg}_{-}{ }^{[12]}, \mathrm{Zr}_{-}{ }^{[13,14]}, \mathrm{Be}^{-[15]}$, $\mathrm{Fe}^{-[16]}, \mathrm{Pd}-\mathrm{Cu}_{-}{ }^{[17]}, \mathrm{Ti}_{-}^{\left[{ }^{[18]}\right.}, \mathrm{Ni}_{-}{ }^{[19]}, \mathrm{Co}^{-[16]}$ and $\mathrm{Cu}_{-}{ }^{[20]}$ based the systems by various slow cooling producing processes such as copper mold casting and water quenching etc. Among these bulk metallic glass systems, Zr-based alloy systems are the most important alloy systems because it conjuncts the achievement of various useful engineering properties with high glass-forming ability. Xingguo Zhang and his colleagues developed a new continuous casting method for the massive production of bulk metallic glass ingot with centimeter-scale diameter while has no limitation in length ${ }^{21}$ in their research paper. An intermittent withdrawal procedure was practiced for continuous casting of bulk metallic glass. The new continuous casting method can provide a cooling speed as fast as that provided by die mold casting method.

However, the solidification process is difficult to be measured and recorded in the surrounding of high temperature and vacuum. The complicated conditions of BMG fabrication which requires a rapid cooling rate also increase the difficulty to study the temperature field. The method of numerical simulation provide a possibility to measure and investigate the thermal parameters and cooling rate of the metallic glass. Thus, the method of numerical simulation is an effective,

*e-mail: jiafei@dlut.edu.cn low-cost and time-saving way to study the solidification process of continuous casting for the production of bulk metallic glass ingot.

In this paper, the temperature field of continuous casting ingot of bulk metallic glass was selected as a research object. The analysis will be given after comparing the results of the numerical simulation with the experimental results. As a finite element analysis software, ANYSYS was used to study the effects of processing parameters on the temperature field and provide theoretical basis for optimizing the solidification process.

\section{Experimental Procedure}

Alloy ingots with nominal compositions of $\mathrm{Zr}_{48} \mathrm{Cu}_{36} \mathrm{Al}_{8} \mathrm{Ag}_{8}$ were prepared by arc melting mixtures of $\mathrm{Zr}, \mathrm{Cu}, \mathrm{Al}$ and $\mathrm{Ag}$ with a purity of $99.99 \%, 99.99 \%, 99.99 \%$ and $99.9 \%$, respectively, in a Zr-gettered high purity argon atmosphere. Ribbon samples were prepared by melt spinning. The thermal stability associated with glass transition, super cooled liquid region and crystallization was examined by differential scanning calorimeter (DSC) at a heating rate of $0.67 \mathrm{~K} / \mathrm{s}$. The device of continuous casting is shown in Figure 1, each ingot was melted four times in the arc meter to avoid the chemical heterogeneity and remolded in the graphite crucible inside the furnace, the molten metal is solidified in the mold which is made of a composite of graphite tube and copper, withdrawing speed is control by withdrawing device. Cylindrical rod samples with a diameter of $10 \mathrm{~mm}$ were prepared by this continuous casting method in an argon atmosphere. The Optical microstructure were obtained with optical microscopy $(\mathrm{OM})$, the etching for $\mathrm{OM}$ observation specimens was made in an aqueous fluoride solution for $5 \mathrm{~s}$ at $298 \mathrm{~K}$. The structure of the as-cast samples was examined by $\mathrm{X}$-ray diffraction (XRD) with $\mathrm{Cu}-\mathrm{K} \alpha$ source. 


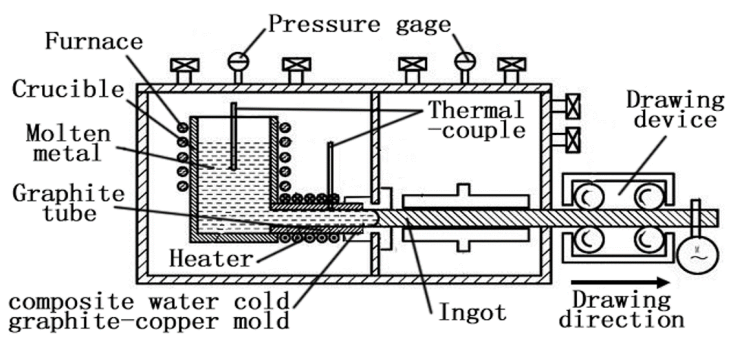

Figure 1. Schematic of continuous casting machine.

\section{Mathematical Model Formulation}

\subsection{Basic assumptions in modeling}

(1) The continuous process is continual and stable, meanwhile, the composition of the molten metal is constant;

(2) The heat transfer on the diameter direction was considered, the heat transfer on the drawing direction was neglected;

(3) The area of the cross section is recognized constant, the heat transfer and solidification was analyzed, the influences of shrinkage and turbulent flow inside the molten alloy during solidification process was neglected;

(4) The latent heat of crystallization was neglected;

(5) The calculating area is selected as the $1 / 4$ cross section of casting due to its geometric symmetry;

(6) For casting velocity item, adopting time -varying boundary conditions and the casting velocity is recognized constant.

\subsection{Heat transfer equation}

The temperature field during casting was calculated based on the heat conduction differential equation of Fourier three-dimensional unsteady heat conduction equation ${ }^{22}$ :

$$
\begin{aligned}
& \frac{\partial}{\partial x}\left(k(T) \frac{\partial T}{\partial x}\right)+\frac{\partial}{\partial y}\left(k(T) \frac{\partial T}{\partial y}\right)+\frac{\partial}{\partial z}\left(k(T) \frac{\partial T}{\partial z}\right)+ \\
& \dot{q}-\rho c_{p} v \frac{\partial T}{\partial z}=\rho C_{p}(T) \frac{\partial T}{\partial t}
\end{aligned}
$$

Where $x, y$ and $z$ are spatial coordinate axes; $T$ is temperature; $k(\mathrm{~T})$ is the heat transfer coefficient variation with temperature; $q$ is the heat resource inside the casting; $\rho$ is the density; $C_{p}(T)$ is the specific heat capacity variation with temperature; $t$ is the time; $\rho c_{p} v \frac{\partial T}{\partial z}$ is heat transfer cause by the movement of the casting.

Based on the assumptions above, by the selection of a micro unit and the movement with the casting in the same velocity, the two-dimension cross section heat conduction equation of the casting could be simplified as:

$$
\frac{\partial}{\partial x}\left(k(T) \frac{\partial T}{\partial x}\right)+\frac{\partial}{\partial y}\left(k(T) \frac{\partial T}{\partial y}\right)=\rho C_{p}(T) \frac{\partial T}{\partial t}
$$

\subsection{Initial and boundary conditions}

In this paper, the first and second categories boundary conditions for the analysis of solidification process of molten metal in the water cold graphite-copper mold can be classified as follow:

The boundary conditions in graphite tube:

$$
\left.\mathrm{T}\right|_{\Gamma}=\mathrm{T}_{0} ;\left.\mathrm{T}\right|_{\Gamma}=\mathrm{f}(\mathrm{r}, \theta, \mathrm{t}) ;\left.T\right|_{\Gamma}=\mathrm{f}(r, \theta, t)
$$

$\Gamma$ is the boundary of object; $T_{0}$ is known temperature; $f(r, \theta, t)$ is a function of known temperature.

The heat flow $\left(\mathrm{W} / \mathrm{m}^{2}\right)$ of casting surface can be deduced by a function of time that the casting stay in the composite water cold copper-graphite mold, according to the actual experiment conditions, the specific parameters of the mold and the velocity of drawing, the heat flux density function has been calculated as:

$\mathrm{q}=\mathrm{A}-\mathrm{B} \sqrt{\mathrm{t}}$

Where $q$ is heat flux density; $A$ is the heat flux density of initial cross section at the inlet of the mold; $B$ is a heat transfer coefficient; $t$ is the time casting staying in the composite water cold copper-graphite mold.

The numerical simulation can be calculated based on the boundary condition of heat flux varied with time after ascertaining the value of $A$ and $B$. It is recognized that the local heat flux density between the molten metal and cooling water is equal to the local heat flux density between the casting and the composite water cold copper-graphite mold:

$$
\begin{aligned}
& \mathrm{q}=\frac{\mathrm{Ts}-\mathrm{Tw}}{\mathrm{Rs}+\mathrm{Rc}+\frac{1}{\mathrm{~h}_{\mathrm{w}}}} \\
& \mathrm{R}_{\mathrm{s}}=\sigma_{\mathrm{s}} / \lambda_{\mathrm{s}}
\end{aligned}
$$

$\mathrm{R}_{\mathrm{c}}=\sigma_{\mathrm{c}} / \lambda \mathrm{c}$

$\mathrm{T}_{\mathrm{s}}$ is the solidus temperature of the molten metal, $\mathrm{T}_{\mathrm{w}}$ is the temperature of the cooling water, $\mathrm{R}_{\mathrm{s}}$ is the heat resistance of graphite tube, $\sigma_{\mathrm{s}}$ is the thickness of graphite tube, $\lambda_{\mathrm{s}}$ is the heat conductive coefficient of graphite tube, $R_{c}$ is the heat resistant of the copper mold, $\sigma_{c}$ is the thickness of copper mold, $\lambda_{c}$ is the heat transfer coefficient of copper mold, $h_{w}$ is the heat transfer coefficient between copper mold and cooling water.

$\mathrm{h}_{\mathrm{w}}=0.023 \frac{\lambda_{\mathrm{w}}}{\mathrm{D}}\left(\frac{\rho_{\mathrm{w}} \mathrm{u}_{\mathrm{w}} \mathrm{D}}{\mu_{\mathrm{w}}}\right)^{0.8}\left(\frac{\mathrm{C}_{\mathrm{pw}} \mu_{\mathrm{w}}}{\lambda_{\mathrm{w}}}\right)^{0.4}$

$\mathrm{D}$ is the diameter of water flow inside the mold; $\lambda_{\mathrm{w}}$ is the heat transfer coefficient of water; $\rho_{w}$ is the density of water; $u_{w}$ is the average flow rate of water; $\mu_{w}$ is the viscosity of water; $\mathrm{C}_{\mathrm{pw}}$ is the specific heat of water; according to Equation 4 and 5,when $\mathrm{t}=0, \mathrm{~A}=q_{0}$ (means $\mathrm{A}$ is recognized to be the heat flux density of initial cross section at the inlet of the mold.

$$
A=\frac{T s-T w}{R_{s}+R_{c}+1 / h_{w}}
$$


After calculations, $\mathrm{Q}_{1}$ (heat inside the mold) is equal to $\mathrm{Q}_{2}$ (heat taken by water)

$$
\begin{aligned}
& \mathrm{Q}_{1}=\operatorname{Lh}\left(\mathrm{A}-\frac{2}{3} \mathrm{~B} \sqrt{\mathrm{h} / \mathrm{v}}\right) \\
& \mathrm{Q}_{2}=\mathrm{C}_{\mathrm{pw}} \mathrm{w} \rho_{\mathrm{w}} \Delta \mathrm{T}
\end{aligned}
$$

$L$ is the inner girth of composite water cold copper-graphite mold; $h$ is the height of composite water cold copper-graphite mold; $v$ is the speed of drawing the casting; $w$ is the velocity of water flow; $\Delta \mathrm{T}$ is the temperature difference of cooling water. Thus:

$B=\left(\operatorname{Lh} A-C_{p w} w \rho_{w} \Delta T\right) \frac{3 v^{\frac{1}{2}}}{2 \operatorname{Lh}^{\frac{3}{2}}}$

Every parameter in the calculation of heat flux density in this paper is shown in Table 1.

\section{Numerical Simulation of Temperature Field}

\subsection{Outline of continuous casting numerical simulation}

According to the analysis of $\mathrm{Zr}$-based BMG thermal parameters and the mathematics model established above, the temperature field of $\mathrm{Zr}_{48} \mathrm{Cu}_{36} \mathrm{Al}_{8} \mathrm{Ag}_{8} \mathrm{BMG}$ during continuous casting process was simulated by ANSYS, the specific steps are listed below. Cooling rate is an essential factor during the continuous casting process, and rapid cooling is beneficial to obtain a full glass structure. But in the meanwhile, with the decreasing of temperature, the viscosity of the molten metal was increasing rapidly, which led to a bad mold filling and failure. In order to solve this problem, a composite graphite-copper mold was used to achieve both of rapid cooling speed and favorable mold filling.

Step 1: Establishing two-dimensional geometric model of casting;

Step 2: Typing in the thermal parameters of alloy;

Step 3: Plotting the finite element mesh;

Step 4: Appling the initial and boundary condition;

Step 5: Solving the temperature field of casting in the graphite tube;
Step 6: Substituting the result into solidification model as the initial condition;

Step 7: Appling the boundary condition of heat flux density;

Step 8: Solving the temperature field of the casting in the copper mold;

Step 9: Discussion and analysis;

Step 10: Experimental verification.

\subsection{Geometric model and mesh plotting}

Due to the symmetric shape of casting, the meshes of a quarter of the ingot were plotted by ANSYS, shown in Figure 2.

\subsection{Simulation results and analysis}

The heat analysis model of ANSYS was used, the unit type as PLANE55 and analysis type as Transient was selected. The initial temperature was applied by command stream BFUNIF, TEMP or Solution, Define Loads, Apply, Thermal, Temperature, Uniform Temp.

Figure 3 denotes that the cooling rate on the surface is the fastest and it decrease gradually along the radial direction from the surface to the inside. Then the temperature differences become smaller as time passed and the temperature field

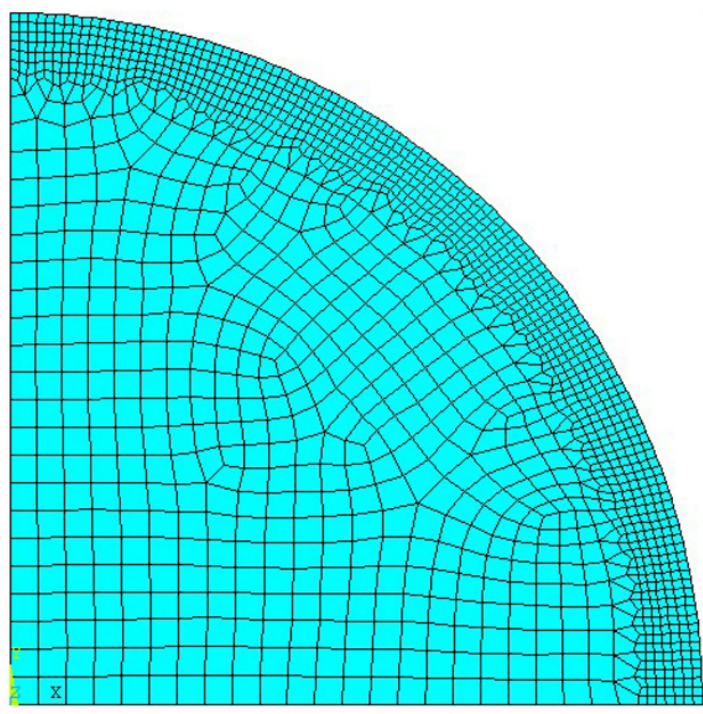

Figure 2. Finite element model of casting.

\begin{tabular}{|c|c|c|c|c|}
\hline Parameters/Unit & $\mathbf{T} / \mathbf{K}$ & $\mathbf{T}_{\mathbf{w}} / \mathbf{K}$ & $\mathbf{R}_{\mathrm{c}} / \mathbf{m}^{2} \mathbf{K} \mathbf{w}^{-1}$ & $\mathbf{R}_{\mathrm{s}} / \mathbf{m}^{2} \mathbf{K} \mathbf{w}^{-1}$ \\
\hline \multirow[t]{7}{*}{ Value } & 821 & 288 & $7.5 \times 10^{-5}$ & $1.55 \times 10^{-5}$ \\
\hline & $\mathrm{D} / \mathrm{m}$ & $\lambda w / \mathrm{Wm}^{-1} \mathrm{~K}^{-1}$ & $\rho_{\mathrm{w}} / \mathrm{kgm}^{-3}$ & $\mathrm{u}_{\mathrm{w}} / \mathrm{ms}^{-1}$ \\
\hline & 0.023 & 0.618 & 998.2 & 0.0684 \\
\hline & $\mathrm{C}_{\mathrm{pw}} / \mathrm{Jkg}^{-1} \mathrm{~K}^{-1}$ & $\mathrm{~L} / \mathrm{m}$ & $\mathrm{h} / \mathrm{m}$ & $\mathrm{W} / \mathrm{m}^{3} \mathrm{~s}^{-1}$ \\
\hline & 4183 & 0.0314 & 0.04 & $8.33 \times 10^{-5}$ \\
\hline & $\mathrm{h}_{\mathrm{w}} / \mathrm{Wm}^{-2} \mathrm{~K}^{-1}$ & $\mu_{\mathrm{w}} / \mathrm{PaS}$ & $\Delta \mathrm{T} / \mathrm{K}$ & \\
\hline & 525.2 & $7.921 \times 10^{-4}$ & 1 & \\
\hline
\end{tabular}

Table 1. The parameters in heat flux density. 
becomes regular and stable in $5 \mathrm{~s}$. It predicts that the graphite has a cooling effect to the molten metal.

The final temperature of molten metal in the exit of the graphite tube was selected as the initial condition; the order of Solution |Define Loads | Apply | Thermal | Temperature | Heat Flux $\mid$ On Lines was applied as the boundary condition of heat flux density with loading the function of heat flux density which was established before. By solving the Euler equation, the total computation time is $26 \mathrm{~s}$.

In Figure 4, the radial temperature distribution of casting has been entered the composite water cold copper-graphite mold for $0.1 \mathrm{~s}, 5 \mathrm{~s}, 15 \mathrm{~s}, 26 \mathrm{~s}$ respectively, which predict the change and cooling rate of the casting during continuous casting. The temperature of the molten metal began to decrease after entering the composite water cold copper-graphite mold. The cooling rate of the exterior is faster than the cooling rate of the interior, and the temperature of whole casting drops below the glass forming temperature after $26 \mathrm{~s}$.

Figure 5 shows the relationship between withdrawing speed and cooling rate of continuous casting under the conditions of $T_{P}=1223 \mathrm{~K}$ and $\mathrm{Q}=5 \mathrm{~L} / \mathrm{min}$. With the withdrawing speed increasing from $1 \mathrm{~mm} / \mathrm{s}$ to $1.5 \mathrm{~mm} / \mathrm{s}$ and $2 \mathrm{~mm} / \mathrm{s}$, the average cooling rate between $T_{M}$ and $T_{G}$ decrease from $28 \mathrm{~K} / \mathrm{s}$ to $24 \mathrm{~K} / \mathrm{s}$ and $21 \mathrm{~K} / \mathrm{s}$.

\section{Experimental Process}

\subsection{Experiment of continuous casting}

In order to keep the coherence and pureness of the alloy, the $\mathrm{Zr}_{48} \mathrm{Cu}_{36} \mathrm{Al}_{8} \mathrm{Ag}_{8}$ alloy is remelted in graphite crucible under high purity argon atmosphere, at a rated temperature of $1223 \mathrm{~K}$ for $30 \mathrm{~min}$ before the rod is withdrawn at different speeds to offer the molten metal a fluctuant cooling rate. The weight of the alloy remains between $300 \mathrm{~g}$ and $350 \mathrm{~g}$. The pouring temperature $\left(T_{P}\right)$ is $1223 \mathrm{~K}$, and soaking time $30 \mathrm{~min}$, flow speed of cooling water $(Q) 5 \mathrm{~L} / \mathrm{min}$, and drawing speed $1 \mathrm{~mm} / \mathrm{s}, 1.5 \mathrm{~mm} / \mathrm{s}$, and $2 \mathrm{~mm} / \mathrm{s}$ respectively for No. 1\#, No.2\#, and No.3\# samples.

\subsection{Results and analysis of the experiment}

The No. 1\# rod sample for continuous casting experiment is shown in Figure 6, and the XRD sample was taken from the blaze position of the rod, as shown in Figure 6. A typical diffuse scattering peak which indicates a fully amorphous structure can be seen. When the rod sample was under the conditions of $T_{P}=1223 \mathrm{~K}, Q=5 \mathrm{~L} / \mathrm{min}$, with an applied drawing speed of $1 \mathrm{~mm} / \mathrm{s}$, the temperature of molten metal in the graphite tube(before entering the mold) decreased, which led to the increase in its viscosity, due to the low drawing speed. Therefore, the rod sample made it easy to get abruption under semisolid condition.

The optical micrograph of the cross section is shown in Figure 6. No crystal phase was found in the cross section, which is consistent with XRD result.

The No. 2\# rod sample for continuous casting experiment is shown in Figure 7. The XRD samples were taken from these five positions of the rod, as shown in Figure 7. A typical diffuse scattering peak which indicates a fully amorphous structure can be seen.

As shown in Figure 7, a diffuse scattering peak appeared at about $2 \theta=38.1^{\circ}$, and there was no crystal diffraction peak found. OM images in different multiples are shown in Figure 7. It can be seen that no crystal phase was found in the whole zone, indicating that the sample had a single-phase amorphous structure.

Figure 8 shows the DSC curves of the $\mathrm{Zr}_{48} \mathrm{Cu}_{36} \mathrm{Ag}_{8} \mathrm{Al}_{8}$ glassy alloy, with $T_{G}=703 \mathrm{~K}$ and $T_{X}=801 \mathrm{~K}$. Both of them are marked with arrows respectively, with $\Delta T=98 \mathrm{~K}$. The glassy sample exhibits a distinct endothermic heat event characteristic of the glass transition, followed by exothermic transformation from the undercooled liquid to the equilibrium crystalline phases.

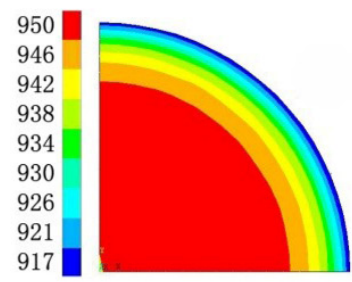

(a)

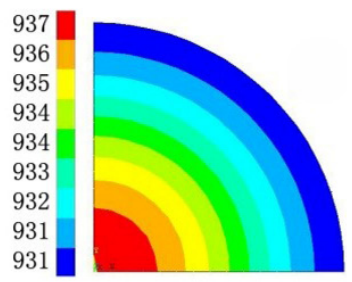

(b)
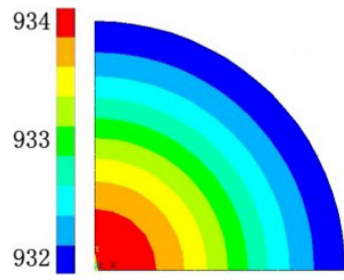

(c)

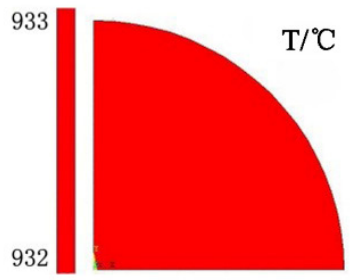

(d)

Figure 3. Temperature distribution contour at different time in the graphite mould (a) $0.1 \mathrm{~s}$, (b) $2.5 \mathrm{~s}$, (c) $4.5 \mathrm{~s}$, (d) $5 \mathrm{~s}$.

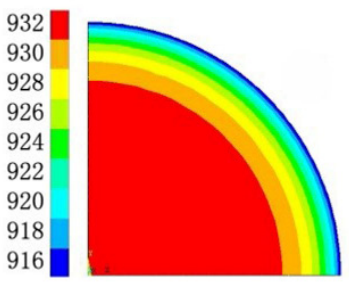

(a)

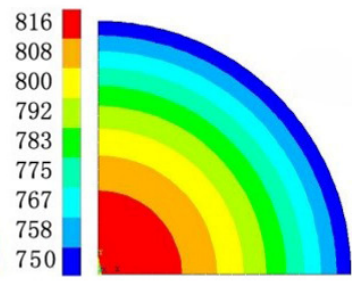

(b)

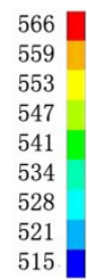

515

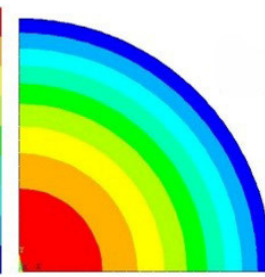

(c)

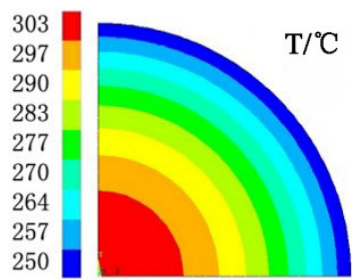

(d)

Figure 4. Temperature distribution contour at different time (a) $0.1 \mathrm{~s}$, (b) $5 \mathrm{~s}$, (c) $15 \mathrm{~s}$, (d) $26 \mathrm{~s}$. 


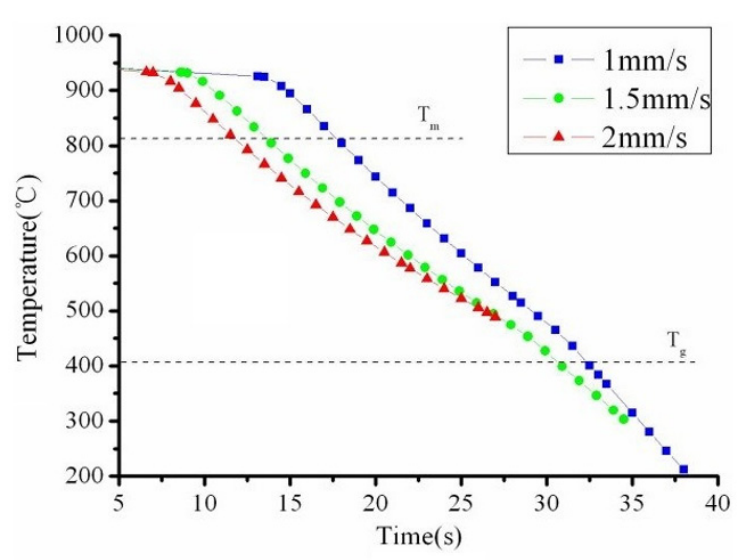

Figure 5. Temperature-Time curve of the hot point with different casting speeds.

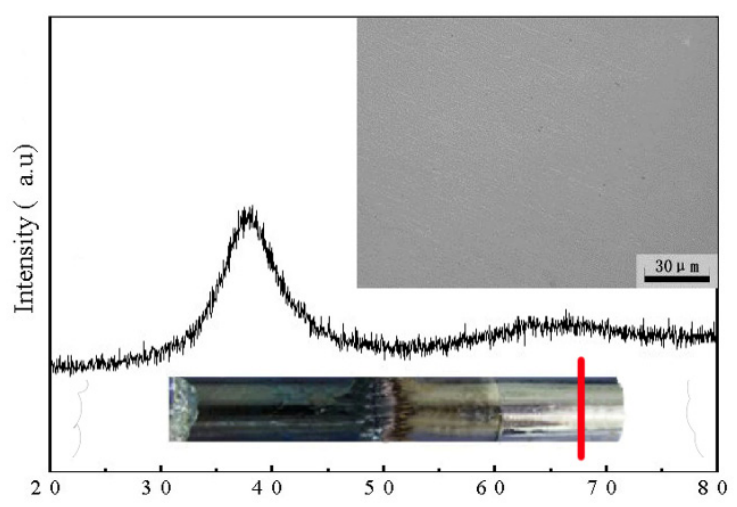

Figure 6. XRD patterns of samples from blaze positions. The insets illustrate the $\mathrm{Zr}_{48} \mathrm{Cu}_{36} \mathrm{Al}_{8} \mathrm{Ag}_{8}$ alloy rod and optical microstructure of the cross section.

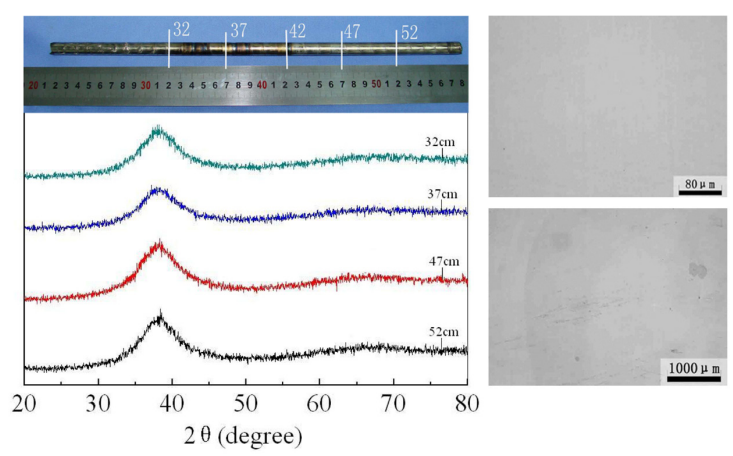

Figure 7. XRD patterns of samples from different positions of $\mathrm{Zr}_{48} \mathrm{Cu}_{36} \mathrm{Ag}_{8} \mathrm{Al}_{8}$. The insets illustrate the sample of $\mathrm{Zr}_{48} \mathrm{Cu}_{36} \mathrm{Ag}_{8} \mathrm{Al}_{8}$ alloy rod and optical microstructures of the cross sections.

The No. 3\# rod sample for continuous casting experiment is shown in Figure 9. The XRD samples were taken from these five positions of the rod, as shown in Figure 9. There was a crystal phase in each cross section to different extents, and the crystallization behavior increased with the casting progresses. The main reason lies in that the drawing speed is too fast to provide enough time for cooling down the

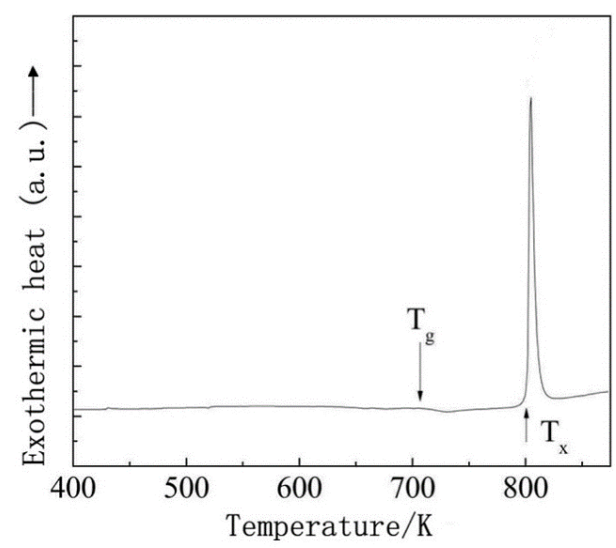

Figure 8. DSC curve of continuous casting $\mathrm{Zr}_{48} \mathrm{Cu}_{36} \mathrm{Ag}_{8} \mathrm{Al}_{8}$ alloy rod.
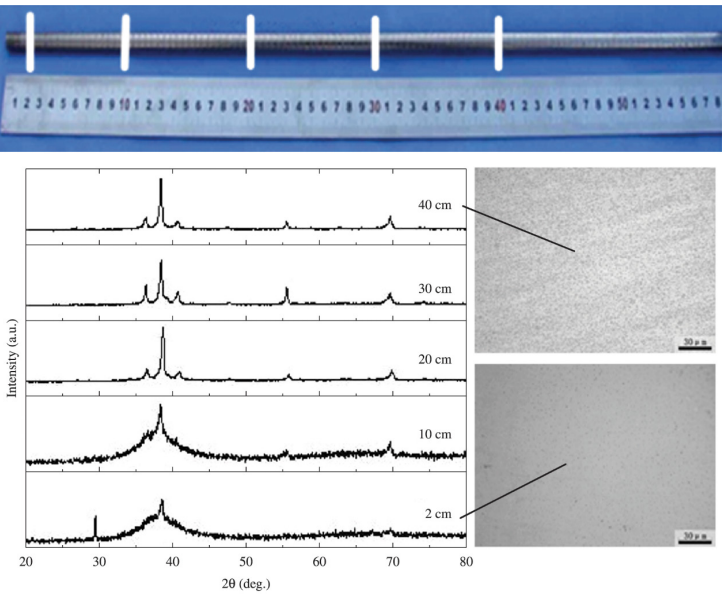

Figure 9. XRD patterns of samples from different positions of $\mathrm{Zr}_{48} \mathrm{Cu}_{36} \mathrm{Ag}_{8} \mathrm{Al}_{8}$. The insets illustrate the sample of $\mathrm{Zr}_{48} \mathrm{Cu}_{36} \mathrm{Ag}_{8} \mathrm{Al}_{8}$ alloy rod and optical microstructures of the cross sections.

molten metal, which remains at a quite high temperature and has left the mold. Besides, the casting releases a lot of heat and affects the subsequent solidification process due to the crystallization behavior.

The sample of optical micrograph was taken at the initial and the end of the casting respectively, as shown in Figure 9. It can be seen that few crystal phase precipitated at the initial stage, while there were much more crystal phases at the end of the casting.

\subsection{Comparison between numerical results and experimental results}

Cooling rate is a significant factor for glass forming. A fully glassy structure could be obtained when the temperature of the molten metal has dropped below that of amorphous transfer at a cooling rate higher than the critical cooling rate of the alloy. The simulation of continuous casting is calculated under the conditions of ${ }_{\mathrm{Tp}}=1223 \mathrm{~K}$ and $Q=5 \mathrm{~L} / \mathrm{min}$, when the drawing speed is applied at $1 \mathrm{~mm} / \mathrm{s}, 1.5 \mathrm{~mm} / \mathrm{s}$, and $2 \mathrm{~mm} / \mathrm{s}$, respectively. The simulation and experimental results were compared with each other and analyzed as follows: 
In this experiment, the average cooling rate of the casting remained at about $28 \mathrm{~K} / \mathrm{s}$ between $\mathrm{T}_{\mathrm{m}}$ and $\mathrm{T}_{\mathrm{g}}$, when the drawing speed was $1 \mathrm{~mm} / \mathrm{s}$, and the temperature of the casting surface decreased to the temperature of glass transfer after its entering the composite water cold copper-graphite mold for about $17 \mathrm{~s}$, while the casting center would cost $19 \mathrm{~s}$. However, both of them met the condition of the glass forming of $\mathrm{Zr}_{48} \mathrm{Cu}_{36} \mathrm{Ag}_{8} \mathrm{Al}_{8}$ alloy.

The average cooling rate of the casting remained at about $24 \mathrm{~K} / \mathrm{s}$ between $T_{M}$ and $T_{G}$ when the drawing speed was $1.5 \mathrm{~mm} / \mathrm{s}$. The temperature of the casting decreased to $T_{G}$ at the position of $6 \mathrm{~mm}$ away from the end of the mold, whereas the temperature of the casting center decreased to $575 \mathrm{~K}$ which was lower than $T_{G}$ and met the condition of glass forming at the end of the mold. $\mathrm{A} \mathrm{Zr}_{48} \mathrm{Cu}_{36} \mathrm{Ag}_{8} \mathrm{Al}_{8}$ alloy rod with a diameter of $10 \mathrm{~mm}$ and length of $380 \mathrm{~mm}$ was fabricated at a drawing speed of $1.5 \mathrm{~mm} / \mathrm{s}$ in this experiment. This sample was determined as a $\mathrm{Zr}_{48} \mathrm{Cu}_{36} \mathrm{Ag}_{8} \mathrm{Al}_{8}$ bulk glass metal with the method of XRD.

The average cooling rate of the casting remained at about $21 \mathrm{~K} / \mathrm{s}$ between $\mathrm{T}_{\mathrm{m}}$ and $T_{G}$ when the drawing speed was $2 \mathrm{~mm} / \mathrm{s}$. At the exit of the mold, the temperatures of casting center and surface were $763 \mathrm{~K}$ and $729 \mathrm{~K}$ respectively, both of them higher than $T_{G}$ and lower than $T_{X}$. The casting will crystallize when the temperature stay above $T_{G}$, and the crystallization behavior will affect the temperature field and lead to more crystallization behavior.

\section{References}

1. Park H-S, Nam H and Yoon JK. Numerical analysis of fluid flow and heat transfer in the parallel type mold of a thin slab caster. ISIJ International. 2001; 41(9):974-980.

2. Ghiţă C, Pop N and Popescu IN. Existence result of an effective stress for an isotropic visco-plastic composite. Computational Materials Science. 2012; 64(11):52-56. http://dx.doi.org/10.1016/j. commatsci.2012.03.058.

3. Crăciun EM, Carabineanu A and Peride N. Antiplane interface crack in a pre-stressed fiber-reinforced elastic composite. Computational Materials Science. 2008; 43(1):184-189. http:// dx.doi.org/10.1016/j.commatsci.2007.07.028.

4. Ionescu A, Nicolicescu C, Bucşe I and Ghercioiu J. Modelling and simulating the pressing process of iron powders with different particle sizes. In: International Conference on Economic Engineering and Manufacturing Systems. 2011; Craiova. Craiova: University of Craiova; 2011. p. 307-310.

5. Dagner J, Friedrich J and Müller G. Numerical study on the prediction of microstructure parameters by multi-scale modeling of directional solidification of binary aluminum-silicon alloys. Computational Materials Science. 2008; 43(4):872-885. http:// dx.doi.org/10.1016/j.commatsci.2008.02.002.

6. Telford M. The case for bulk metallic glass. Materials Today. 2004; 7(3):36-43. http://dx.doi.org/10.1016/S1369-7021(04)00124-5.

7. Fujita K, Hashimoto T, Zhang W, Nishiyama N, Ma C, Kimura $\mathrm{HM}$, et al. Advanced high-strength and ductile Fe-Cr-MoGa-Si alloys. Reviews on Advanced Materials Science. 2008; 18(2):140-143

8. Kumar G, Tang HX and Schroers J. Nanomoulding with amorphous metals. Nature. 2009; 457(7231):868-872. http:// dx.doi.org/10.1038/nature07718. PMid:19212407.

\section{Conclusion}

According to the results of the numerical simulation, the variation of drawing speed significantly affects the final distribution of temperature field. The cooling rate decreases while the final temperature of casting rises with the increase in drawing speed. The experiment was conducted under the following conditions: The pouring temperature is $1223 \mathrm{~K}$, flow speed of cooling water $5 \mathrm{~L} / \mathrm{min}$, applied drawing speed at $1 \mathrm{~mm} / \mathrm{s}, 1.5 \mathrm{~mm} / \mathrm{s}$, and $2 \mathrm{~mm} / \mathrm{s}$, respectively, as well as the average cooling rate of the molten metal between $T_{M}$ and $T_{G}$ at about $28 \mathrm{~K} / \mathrm{s}, 24 \mathrm{~K} / \mathrm{s}$ and $21 \mathrm{~K} / \mathrm{s}$, respectively, which meet the condition of glass forming. The rod sample with a processing parameter of $1 \#$ cooled down and became sticky, hindering the subsequent mold filling and easily leading to the failure due to the low speed. The rod sample with a processing parameter of $3 \#$ exhibited blaze metallic luster. However, the drawing speed was too fast to provide enough time for forming metallic glass. The rod sample with a processing parameter of 3\# was a fully Zr-based bulk metallic glass with a diameter of $10 \mathrm{~mm}$ and length of $380 \mathrm{~mm}$, which would be a desirable production for horizontal continuous casting.

\section{Acknowledgements}

The research was financially supported by the National Natural Science Foundation of China (Grant No. 51301029 and 51375071) and the Fundamental Research Funds for the Central Universities (DUT11RC(3)86).

9. Saotome Y, Okaniwa S, Kimura HM and Inoue A. Superplastic nanoforging of Pt-based metallic glass with dies of $\mathrm{Zr}-\mathrm{BMG}$ and glassy carbon fabricated by focused ion beam. Materials Science Forum. 2007; 539-543:2088-2093. http://dx.doi. org/10.4028/www.scientific.net/MSF.539-543.2088.

10. Nishiyama N, Amiya K and Inoue A. Novel applications of bulk metallic glass for industrial products. Journal of NonCrystalline Solids. 2007; 353(32-40):3615-3621. http://dx.doi. org/10.1016/j.jnoncrysol.2007.05.170.

11. Inoue $\mathrm{A}$ and $\mathrm{Zhang} \mathrm{T}$. Fabrication of bulk glassy $\mathrm{Zr}_{55} \mathrm{Al}_{10} \mathrm{Ni}_{5} \mathrm{Cu}_{30}$ alloy of $30 \mathrm{~mm}$ in diameter by a suction casting method. Materials Transactions. 1996; 37(2):185-187. http://dx.doi. org/10.2320/matertrans1989.37.185.

12. Yokoyama Y, Mund E, Inoue A and Schultz L. Production of $\mathrm{Zr}_{55} \mathrm{Cu}_{30} \mathrm{Ni}_{5} \mathrm{Al}_{10}$ glassy alloy rod of $30 \mathrm{~mm}$ in diameter by a cap-cast technique. Materials Transactions. 2007; 48(12):31903192. http://dx.doi.org/10.2320/matertrans.MRP2007164.

13. Zhang W, Zhang QS, Qin CL and Inoue A. Synthesis and properties of Cu-Zr-Ag-Al glassy alloys with high glass-forming ability. Materials Science and Engineering: B. 2008; 148(13):92-96.

14. Johnson WL. Fundamental aspects of bulk metallic glass formation in multicomponent alloys. Materials Science Forum. 1996; 225-227:35-50. http://dx.doi.org/10.4028/www.scientific. net/MSF.225-227.35.

15. Inoue $\mathrm{A}, \mathrm{Nishiyama} \mathrm{N}$ and Kimura HM. Preparation and thermal stability of bulk amorphous $\mathrm{Pd}_{40} \mathrm{Cu}_{30} \mathrm{Ni}_{10} \mathrm{P}_{20}$ alloy cylinder of 72 $\mathrm{mm}$ in diameter. Materials Transactions, JIM. 1997; 38(2):179183. http://dx.doi.org/10.2320/matertrans1989.38.179.

16. Zeng YQ, Nishiyama N, Yamamoto $T$ and Inoue A. Ni-rich bulk metallic glasses with high glass-forming ability and good 
metallic properties. Materials Transactions. 2009; 50(10):24412445. http://dx.doi.org/10.2320/matertrans.MRA2008453.

17. Zheng Q, Xu J and Ma E. High glass-forming ability correlated with fragility of $\mathrm{Mg}-\mathrm{Cu}(\mathrm{Ag})-\mathrm{Gd}$ alloys. Journal of Applied Physics. 2007; 102(11):113519. http://dx.doi.org/10.1063/1.2821755.

18. Li R, Pang S, Ma C and Zhang T. Influence of similar atom substitution on glass formation in ( $\mathrm{La}-\mathrm{Ce}$ )-Al-Co bulk metallic glasses. Acta Materialia. 2007; 55(11):3719-3726. http://dx.doi. org/10.1016/j.actamat.2007.02.026.

19. Jiang QK, Zhang GQ, Chen LY, Wu JZ, Zhang HG and Jiang JZ. Glass formability, thermal stability and mechanical properties of La-based bulk metallic glasses. Journal of Alloys and
Compounds. 2006; 424(1-2):183-186. http://dx.doi.org/10.1016/j. jallcom.2006.07.109.

20. Zhang QS, Zhang $\mathrm{W}$ and Inoue A. Preparation of $\mathrm{Cu}_{36} \mathrm{Zr}_{48} \mathrm{Ag}_{8} \mathrm{Al}_{8}$ bulk metallic glass with a diameter of $25 \mathrm{~mm}$ by copper mold casting. Materials Transactions. 2007; 48(3):629-631. http:// dx.doi.org/10.2320/matertrans.48.629.

21. Zhang T, Zhang X, Zhang W, Jia F, Inoue A, Hao H, et al. Study on continuous casting of bulk metallic glass. Materials Letters. 2011; 65(14):2257-2260. http://dx.doi.org/10.1016/j. matlet.2011.04.033.

22. Mills AF. Heat Transfer. 9th ed. Upper Saddle River: Prentice Hall; 1999. 147 p. 